\title{
Microspectroscopy of ultrafast laser inscribed channel waveguides in Yb:tungstate crystals
}

\author{
F. M. Bain, ${ }^{1, a)}$ W. F. Silva, ${ }^{2}$ A. A. Lagatsky, ${ }_{1}^{1}$ R. R. Thomson, ${ }^{3}$ N. D. Psaila, ${ }^{3}$ A. K. Kar, ${ }^{3}$ \\ W. Sibbett, ${ }^{1}$ D. Jaque ${ }^{4}$ and C. T. A. Brown ${ }^{1}$ \\ ${ }^{1}$ J.F. Allen Physics Research Laboratories, School of Physics and Astronomy, University of St Andrews, \\ St Andrews, Fife, Scotland KY16 9SS, United Kingdom \\ ${ }^{2}$ Instituto de Física, Universidade Federal de Alagoas, 57072-970 Maceió, Alagoas, Brazil \\ ${ }^{3}$ School of Engineering and Physical Science, Heriot-Watt University, David Brewster Building, Edinburgh, \\ Scotland, EH14 4AS, United Kingdom \\ ${ }^{4}$ Fluorescence Imaging Group, Departmento de Física de Materiales C-IV, Universidad Autónoma de \\ Madrid, 28049 Madrid, Spain
}

(Received 2 July 2010; accepted 7 March 2011; published online 7 April 2011)

\begin{abstract}
We report microspectroscopy measurements of crystalline channel waveguides fabricated in $\mathrm{Yb}: \mathrm{KGd}\left(\mathrm{WO}_{4}\right)_{2}$ and $\mathrm{Yb}: \mathrm{KY}\left(\mathrm{WO}_{4}\right)_{2}$ using the ultrafast laser inscription technique. From these measurements we find that densification of the $\mathrm{WO}_{2} \mathrm{~W}$ bridge in the double tungstate crystal lattice is responsible for the refractive index increase, which creates the waveguide confinement. We identified that shifts toward lower energies in the $\sim 760 \mathrm{~cm}^{-1}$ Raman mode indicate regions, which guide light polarized along the crystallographic $\boldsymbol{b}$ axis, while higher energy shifts in the 682 and $898 \mathrm{~cm}^{-1}$ Raman lines correspond to guiding regions for light polarized along the crystallographic $\boldsymbol{a}$ axis. () 2011 American Institute of Physics. [doi:10.1063/1.3573999]
\end{abstract}

Ultrafast laser inscription (ULI) is a technique, which has been used to fabricate channel waveguides in a variety of optical materials, ${ }^{1}$ including crystals such as Ti:sapphire, ${ }^{2}$ $\mathrm{Nd}: \mathrm{Y}_{3} \mathrm{Al}_{5} \mathrm{O}_{12}(\mathrm{Nd}: \mathrm{YAG}){ }^{3}{ }^{3} \mathrm{KGd}\left(\mathrm{WO}_{4}\right)_{2},{ }^{4} \mathrm{Yb}$-doped potassium double tungstates ${ }^{5,6}\left[\mathrm{Yb}: \mathrm{KGd}\left(\mathrm{WO}_{4}\right)_{2}\right.$ and $\left.\mathrm{Yb}: \mathrm{KY}\left(\mathrm{WO}_{4}\right)_{2}\right]$, and $\mathrm{Li}: \mathrm{NbO}_{3}(\mathrm{Li}: \mathrm{NbO})^{7}$ During ULI, ultrashort-pulse radiation is tightly focused inside a dielectric material, resulting in high electric field intensities, which induce nonlinear processes such as multiphoton absorption and avalanche ionization, and lead to high temperatures and pressures through an induced microplasma. The plasma recombines with the lattice through energy transfer and this induces a modification to the material structure. In crystalline materials, this modification often takes the form of a void structure due to expansion of the material in the focal volume. This expansion induces a strain field in the material surrounding the void, which in turn leads to a refractive index modification via the photoelastic effect. However, the physical changes to the crystalline media and the mechanisms responsible for the resulting stress are not well understood. Two nondestructive techniques, which can be used to investigate the induced microscale modifications in the crystalline material are confocal microluminescence ( $\mu$-PL) and micro-Raman ( $\mu$-Raman) measurements. ${ }^{8,9}$ These techniques involve recording the localized luminescence and Raman spectra from small volumes $\left(<1 \mu \mathrm{m}^{3}\right)$ in and around the waveguide structure. By the observation and interpretation of any changes to the output spectra, such as intensity, peak wavelength, and spectral width, information on localized lattice damage, stress, and disorder can be extracted.

Here we report two-dimensional (2D) microspectroscopy mapping of waveguides fabricated in crystalline $\mathrm{Yb}^{3+}: \mathrm{KGd}\left(\mathrm{WO}_{4}\right)_{2} \quad(\mathrm{Yb}: \mathrm{KGdW})$ and $\mathrm{Yb}^{3+}: \mathrm{KY}\left(\mathrm{WO}_{4}\right)_{2}$ (Yb:KYW) using ULI. The structural changes to the lattice,

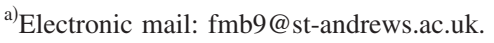

which were responsible for the localized refractive index variation, have been identified.

Details of the waveguide fabrication and their laser performance can be found in Ref. 6. All structures consisted of two tracks inscribed next to each other at a separation of $20 \mu \mathrm{m}$. Microspectroscopy mapping was performed on structures written at different pulse energies, which gave different guiding and lasing performance. It was observed that in $\mathrm{Yb}: \mathrm{KGdW}$, guiding of light polarized along the crystallographic $\boldsymbol{a}$ axis occurred in regions above and below the central crack [Fig. 1(a)], which was formed during waveguide fabrication. Conversely, guiding of light polarized along the crystallographic $\boldsymbol{b}$ axis occurred in left or right hand regions in Yb:KGdW [Fig. 1(b)]. In Yb:KYW no central crack was formed and good guiding was only observed for $\boldsymbol{E} \| \boldsymbol{b}$ in left, central, and right hand regions [Fig. 1(c)].

Microspectroscopy experiments were carried out using a BX-41 fiber-coupled confocal microscope. The $\mathrm{Yb}^{3+}$ ions were excited by focusing a $940 \mathrm{~nm}$ laser beam into the

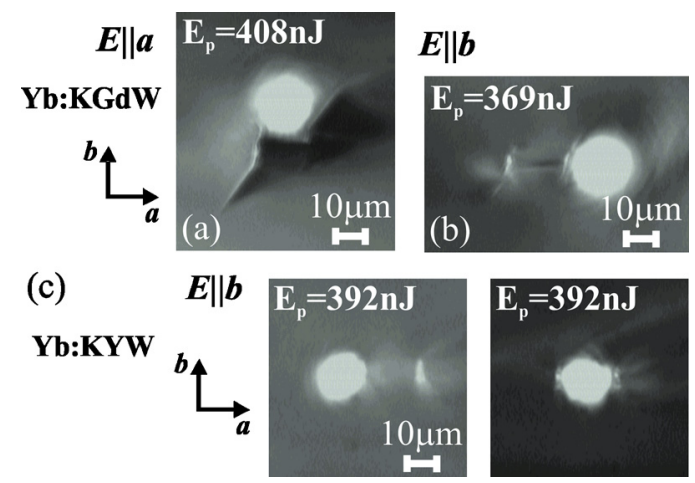

FIG. 1. (Color online) (a) $\boldsymbol{E} \| \boldsymbol{a}$ lasing waveguide in $\mathrm{Yb}: \mathrm{KGdW}$ written at $408 \mathrm{~nJ}$ pulse energy, (b) $\boldsymbol{E} \| \boldsymbol{b}$ lasing waveguide in $\mathrm{Yb}: \mathrm{KGdW}$ written at 369 nJ pulse energy, and (c) lasing waveguides in Yb:KYW for $\boldsymbol{E} \| \boldsymbol{b}$ (inscription pulse energy $392 \mathrm{~nJ})$. 

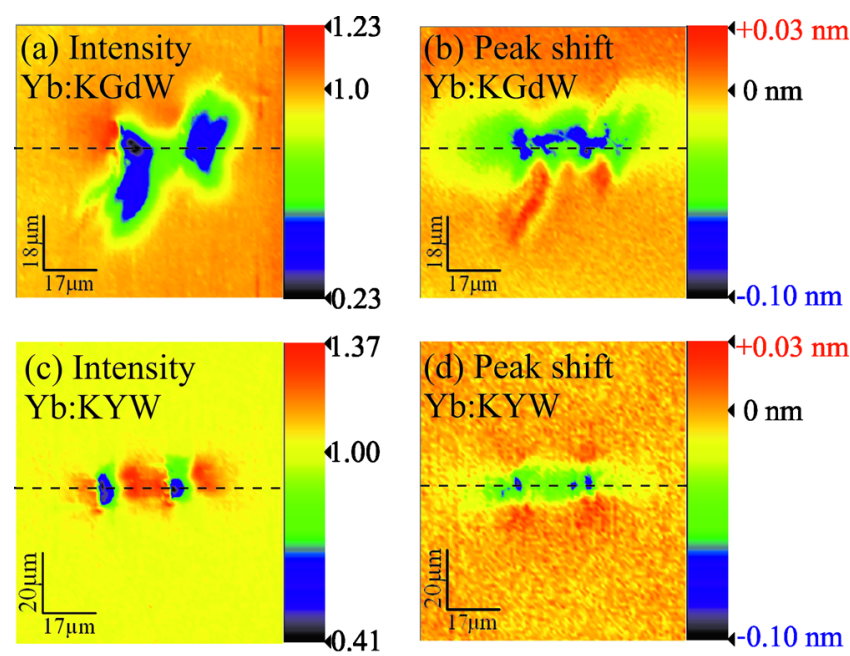

(e)
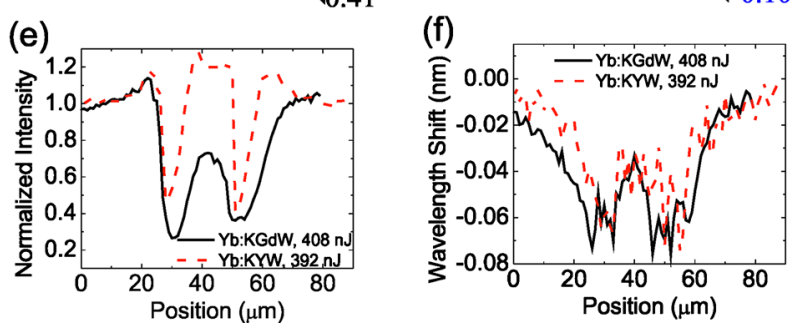

FIG. 2. (Color online) Microluminescence maps of the $980 \mathrm{~nm}$ emission peak of the structures written at $408 \mathrm{~nJ}$ pulse energy in Yb:KGdW [(a) and (c)] and $392 \mathrm{~nJ}$ pulse energy in Yb:KYW [(b)and (d)] showing [(a) and (c)] normalized intensity of the peak and [(b) and (d)] wavelength shift of the peak. Linescans of (e) intensity and (f) peak wavelength shift corresponding to dotted lines in $[(\mathrm{a})-(\mathrm{d})]$.

sample using a $50 \times$ infrared objective [numerical aperture (NA) of 0.55]. The back-generated $\mathrm{Yb}^{3+}$ luminescence (at around $980 \mathrm{~nm}$ ) was collected with the same microscope objective and, after passing through a confocal aperture, was fiber-coupled to a high resolution spectrometer SPEX 500M. For the Raman mapping, excitation was provided by an argon-ion laser operating at $488 \mathrm{~nm}$ and a series of notch filters was used to block the excitation wavelength from the detected signal. Here a $50 \times$ objective, with an NA of 0.75 , was used. 2D maps of the waveguide cross sections, in a plane $5 \mu \mathrm{m}$ below the waveguide end-facets, were recorded, and analysis of the detected peaks was performed using LABSPEC 5. The results were then plotted in WSXM@ ${ }^{10}$

In both $\mathrm{Yb}: \mathrm{KGdW}$ and $\mathrm{Yb}: \mathrm{KYW}$, the luminescence intensity at $980 \mathrm{~nm}$ was found to drop significantly in the written filaments [Figs. 2(a), 2(c), and 2(e)], and in the case of $\mathrm{Yb}: \mathrm{KGdW}$ the intensity was also found to decrease in the central region, where cracking was present [Figs. 2(a) and 2(e)]. This drop in intensity indicates the presence of a damaged network, and, hence a local reduction in the refractive index with respect to the bulk. In Yb:KGdW we observed a greater drop in intensity in the central cracked region of the structure written at $408 \mathrm{~nJ}$ of pulse energy when compared to that written with $369 \mathrm{~nJ}$ of pulse energy. This indicates that, as expected, there was greater damage when writing with higher pulse energies. In both crystals a blueshift in the 980 $\mathrm{nm}$ luminescence peak was observed in the guiding regions [Figs. 2(b), 2(d), and 2(f)]. This indicates a slight change in the crystal field affecting the $\mathrm{Yb}^{3+}$ ions. This, in turn, accounts for a local distortion of the original network due to the presence of a residual stress at filaments and in their
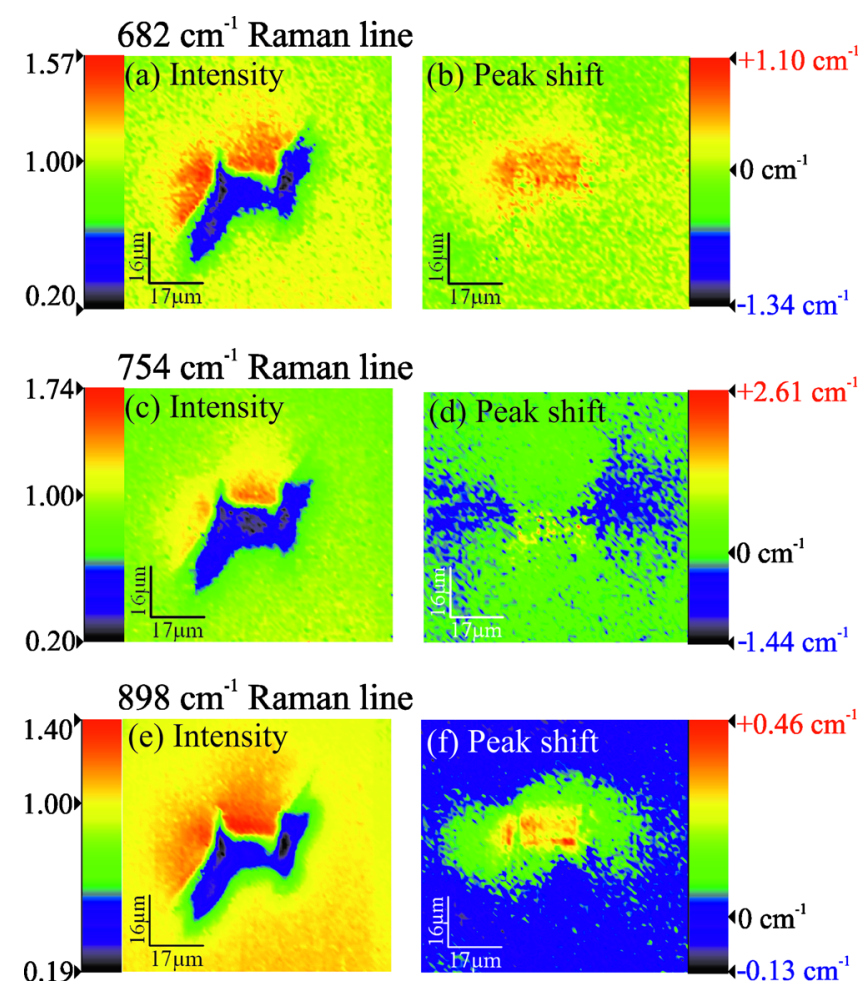

FIG. 3. (Color online) $\mu$-Raman maps in Yb:KGdW of the [(a) and (b)] $682 \mathrm{~cm}^{-1}$, [(c) and (d)] $754 \mathrm{~cm}^{-1}$, and [(e) and (f)] $898 \mathrm{~cm}^{-1}$ frequency shifts, showing $[(a),(c)$, and (e)] normalized intensities of the peaks, [(b), (d), and (f)] variations in the frequency shifts of the peaks.

surroundings. However, further insight into the stress formed in the crystalline lattice can be given by considering the $\mu$-Raman measurements.

In Yb:KGdW, we analyzed the spatial variation in the spectral properties of the Raman modes located at 682,754 , and $898 \mathrm{~cm}^{-1}$ (all associated with vibrations of the $\mathrm{WO}_{2} \mathrm{~W}$ bridge). ${ }^{11}$ The Raman images obtained based on these lines for the structure written with $408 \mathrm{~nJ}$ pulse energy are illustrated in Figs. 3(a)-3(f). The intensity of these Raman modes has been found to decrease in the filaments and in the cracked region between them (appearing for higher writing energies). This reduction in the Raman intensity is associated with the presence of defects that causes bond braking. This is in agreement with the conclusion extracted from the observed reduction in the $\mathrm{Yb}^{3+}$ fluorescence efficiency.

The shift in Raman peak provides more information about the changes to the lattice. It is clear from Figs. 3(b) and 3(f) that the 682 and $898 \mathrm{~cm}^{-1}$ modes shift toward larger vibration energies (by $\sim 0.7 \mathrm{~cm}^{-1}$ and $\sim 0.3 \mathrm{~cm}^{-1}$, respectively) in the region located above the central crack, corresponding to the previously identified $\boldsymbol{E} \| \boldsymbol{a}$ guiding region (see Ref. 6). Conversely, the $754 \mathrm{~cm}^{-1}$ line showed reduced vibration energies $\left(\sim-0.7 \mathrm{~cm}^{-1}\right.$ at $\left.408 \mathrm{~nJ}\right)$ in the left and right hand regions [Fig. 3(d)], which corresponds to the waveguides observed using $\boldsymbol{E} \| \boldsymbol{b}$. In these regions the 682 and $898 \mathrm{~cm}^{-1}$ lines showed small shifts to larger vibration energies. Similar shifts in the $\sim 760$ and $900 \mathrm{~cm}^{-1}$ modes were previously reported in $\mathrm{KGdW}$ guiding regions for $E \| N_{p}$ and $E \| N_{g}$ polarizations. ${ }^{4}$

The $\sim 685$ and $900 \mathrm{~cm}^{-1}$ Raman lines in the double tungstates, $\mathrm{KLn}\left(\mathrm{WO}_{4}\right)_{2}(\mathrm{KLnW})$, where Ln represents a lanthanide, are known to experience a shift to higher vibrational energies upon substitution of heavier lanthanides into the 

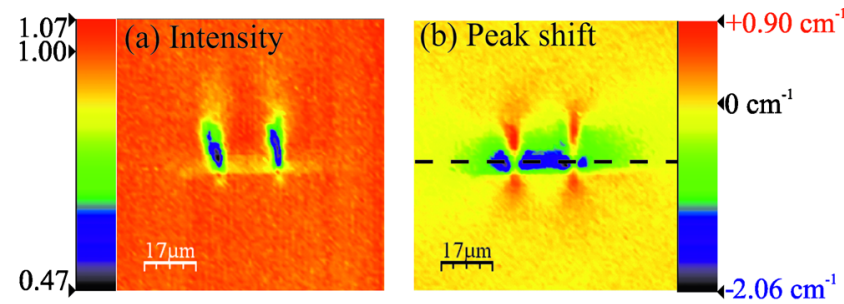

(c) (d)
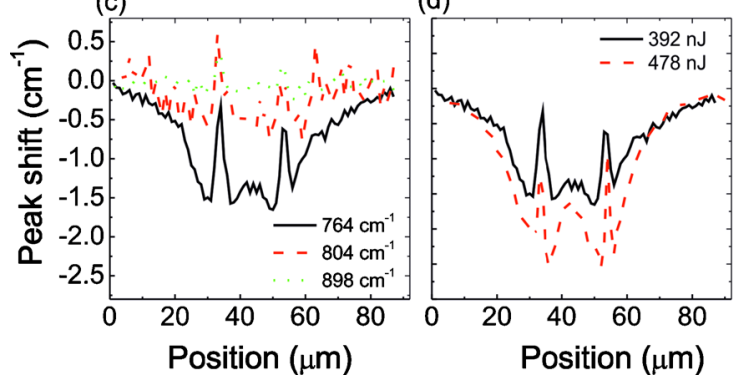

FIG. 4. (Color online) $\mu$-Raman maps in Yb:KYW of the $764 \mathrm{~cm}^{-1}$ line, showing (a) normalized peak intensity, (b) variations in the frequency shift of the peaks. Linescans of (c) frequency shifts in the Yb:KYW Raman lines, where the most significant shift is seen in the $764 \mathrm{~cm}^{-1}$ line, (d) shifts in the $764 \mathrm{~cm}^{-1}$ line in structures written with different pulse energies. The linescans correspond to the dotted lines in (b).

KLnW lattice, which lead to a higher refractive index, while the $\sim 765 \mathrm{~cm}^{-1}$ line is an exception to this and instead shows a reduction in energy upon substitution of heavier lanthanides. ${ }^{12}$ When considering the axis of vibration of the Raman modes ${ }^{11}$ in conjunction with the crystallographic structure $^{13}$ it is apparent that a compression of the tungsten atoms, which lie approximately along the $\boldsymbol{a}$ axis, will lead to a shift in the 682 and $898 \mathrm{~cm}^{-1}$ modes toward larger vibration energies, as these lines correspond to vibrations along the tungsten axis of the bridged oxygen atoms in the $\mathrm{WO}_{2} \mathrm{~W}$ double bond. Meanwhile, as the tungsten atoms are forced together, the oxygen atoms, which lie approximately parallel to the $\boldsymbol{b}$ axis, will be forced apart leading to a shift of the $754 \mathrm{~cm}^{-1}$ mode toward lower vibration energies, as this vibration of the oxygen atoms occurs almost parallel to the $\boldsymbol{b}$ axis. Following this argument the Raman modes at $\sim 760$ and $900 \mathrm{~cm}^{-1}$ would experience opposite shifts under compression of the $\mathrm{WO}_{2} \mathrm{~W}$ double bond, as has indeed been postulated in previous works. ${ }^{4}$

In $\mathrm{Yb}: \mathrm{KYW}$, good guiding regions were only identified for $\boldsymbol{E} \| \boldsymbol{b}$. According to the results obtained in the Yb:KGdW waveguides this should be reflected by a shift toward lower vibration energies of the $764 \mathrm{~cm}^{-1}$ Raman mode. This is indeed what has been observed (Fig. 4): Although all the Raman modes showed a reduction in intensity in the filaments, only the $764 \mathrm{~cm}^{-1}$ line showed a significant peak shift in the regions surrounding the filament [Fig. 4(c)]. In this Raman line a strong blueshift was observed in left, central, and right hand regions, suggesting densification in the $\mathrm{WO}_{2} \mathrm{~W}$ bridge of the lattice and a refractive index increase along the crystallographic $\boldsymbol{b}$ axis as outlined above for $\mathrm{Yb}: \mathrm{KGdW}$. By comparing line scans of the $764 \mathrm{~cm}^{-1}$ peak shifts for structures written at two different energies (392 nJ and $478 \mathrm{~nJ})$ it is apparent that higher writing energies result in greater shifts (shifts of $\sim-1.5 \mathrm{~cm}^{-1}$ and $\sim-2.5 \mathrm{~cm}^{-1}$ are seen, respectively) [Fig. 4(d)], suggesting increased stress at higher writing powers. Interestingly, however, the spatial extent of the shift is similar for both structures, corresponding with the observation that the waveguide mode size was independent of writing energy with consistent diameters of $\sim 12 \mu \mathrm{m}$.

In conclusion, we have used confocal microspectroscopy to map ULI channel waveguides in $\mathrm{Yb}: \mathrm{KGdW}$ and $\mathrm{Yb}: \mathrm{KYW}$. From the results we have been able to identify densification of the $\mathrm{WO}_{2} \mathrm{~W}$ bridge as being responsible for the increased refractive index, which leads to the previously observed waveguide behavior. Different Raman modes have been associated with the distinct guiding regions identified for $\boldsymbol{E} \| \boldsymbol{a}$ and $\boldsymbol{E} \| \boldsymbol{b}$. The 682 and $898 \mathrm{~cm}^{-1}$ lines experience shifts toward larger vibration energies in all guiding regions in $\mathrm{Yb}: \mathrm{KGdW}$ but especially $\boldsymbol{E} \| \boldsymbol{a}$ waveguides, while the $\sim 760 \mathrm{~cm}^{-1}$ lines experience a shift toward lower energies in those regions, which are able to guide $\boldsymbol{E} \| \boldsymbol{b}$ in both $\mathrm{Yb}: \mathrm{KGdW}$ and $\mathrm{Yb}: \mathrm{KYW}$. The role of pulse energy in waveguide formation is also apparent. Larger writing energies are shown to reduce the intensity of luminescence and Raman modes, due to greater damage, and lead to larger peak frequency shifts as a result of the increased stress.

This work was supported by the UK Engineering and Physical Research Council through the Basic Technology Grant No. EP/D04622X/1, the Universidad Autónoma de Madrid and Comunidad Autónoma de Madrid, the Spanish Ministerio de Educación y Ciencia (Grant Nos. MAT201016161, CCG08-UAM/MAT-4434, and PHAMA Program No. P2009/MAT1756), CEAL-Banco Santander, and Brazilian agencies CAPES (Coordenação de Aperfeiçoamento de Pessoal de Nível Superior) and CNPq (Conselho Nacional de Desenvolvimento Científico e Tecnológico).

${ }^{1}$ R. R. Gattass and E. Mazur, Nat. Photonics 2, 219 (2008).

${ }^{2}$ V. Apostolopoulos, L. Laversenne, T. Colomb, C. Depeursinge, R. P. Salathe, M. Pollnau, R. Osellame, G. Cerullo, and P. Laporta, Appl. Phys. Lett. 85, 1122 (2004).

${ }^{3}$ J. Siebenmorgen, K. Petermann, G. Huber, K. Rademaker, S. Nolte, and A. Tunnermann, Appl. Phys. B: Lasers Opt. 97, 251 (2009).

${ }^{4}$ S. M. Eaton, C. A. Merchant, R. Iyer, A. J. Zilkie, A. S. Helmy, J. S. Aitchison, P. R. Herman, D. Kraemer, R. J. D. Miller, C. Hnatovsky, and R. S. Taylor, Appl. Phys. Lett. 92, 081105 (2008)

${ }^{5}$ C. N. Borca, V. Apostolopoulos, F. Gardillou, H. G. Limberger, M. Pollnau, and R. P. Salathé, Appl. Surf. Sci. 253, 8300 (2007).

${ }^{6}$ F. M. Bain, A. A. Lagatsky, R. R. Thomson, N. D. Psaila, N. V. Kuleshov, A. K. Kar, W. Sibbett, and C. T. A. Brown, Opt. Express 17, 22417 (2009).

${ }^{7}$ R. R. Thomson, S. Campbell, I. J. Blewett, A. K. Kar, and D. T. Reid, Appl. Phys. Lett. 88, 111109 (2006).

${ }^{8}$ V. Dierolf and C. Sandmann, J. Lumin. 102-103, 201 (2003).

${ }^{9}$ Y. Zhang, L. Guilbert, and P. Bourson, Appl. Phys. B: Lasers Opt. 78, 355 (2004).

${ }^{10}$ I. Horcas, R. Fernández, J. M. Gómez-Rodríguez, J. Colchero, J. GómezHerrero, and A. M. Baro, Rev. Sci. Instrum. 78, 013705 (2007).

${ }^{11}$ L. Macalik, J. Hanuza, and A. A. Kaminskii, J. Mol. Struct. 555, 289 (2000).

${ }^{12}$ J. Hanuza and L. Macalik, Spectrochim. Acta, Part A 43, 361 (1987).

${ }^{13}$ M. C. Pujol, M. Rico, C. Zaldo, R. Solé, V. Nikolov, X. Solans, M. Aguiló, and F. Díaz, Appl. Phys. B: Lasers Opt. 68, 187 (1999). 